II. Twenty per cent of the world's population consumes $80 \%$ of its wealth and is responsible for $75 \%$ of its pollution. We believe there is sufficient knowledge and technology available to reduce the obscene disparity of wealth. We demand a genuine transfer of knowledge and resources from North to South, rather than the dumping of obsolescent and inefficient technologies and products. There must be an immediate end to the international traffic in toxic waste, urgent reduction of the pollution of rivers and oceans by industrial waste and human sewage, an end to the unprincipled export of banned pesticides and other chemicals to the economically desperate countries of the Third World, and the immediate availability of information and means to allow people, individually and voluntarily, to pursue the goal of population stabilization.

III. Traditional societies are generally the best managers of biodiversity. For the last five hundred years the knowledge and the rights of the native American peoples have been ignored. We believe that respecting the interests of indigenous peoples, both in the Americas and throughout the rest of the world, who have too often and widely become exploited minorities in their own countries, is crucial for the preservation of biological and cultural diversity. We deplore the cultural pollution and loss of tradition which have led to global rootlessness leaving humans, through the intensity of mass-marketing, vulnerable to the pressures of economic and political totalitarianism and habits of mass-consumption and waste which imperil the Earth.

IV. At the Earth Summit of June 1992 we demand that world leaders sign a Global Climate Change Convention.
Industrialized countries must make a minimum commitment to a $20 \%$ reduction of their carbon dioxide emissions by the year 2000 . We insist on rigorous implementation of the Montreal Protocol on Protection of the Ozone Layer. We also urge the signing of a convention to protect biological diversity, and the evidence of concrete progress in negotiations for a global forests treaty.

$\mathrm{V}$. The proven economic folly of nuclear power, coupled to the probability of environmental catastrophe, necessitates the urgent substitution of nuclear energy by clean, safe, and efficient, energy systems. The military establishment must cease the proliferation of nuclear, biological, and chemical, weapons and convert a significant proportion of military expenditure to expenditure on environmental security. To ensure this, we demand an end to secrecy and a right to freedom of information in all matters concerning the world's environment.

The participants at this propitious Symposium emphasize that environmental destruction cannot be confined within the boundaries of any nation state. We urge our fellow writers, environmentalists and other scientists, members of indigenous minorities, and all concerned people, to join us in demanding the creation of the aboveproposed International Court of the Environment at which environmentally criminal activity can at least be brought to the attention of the entire world.

ADAM MARKHAM, Head
Resource Consumption \& Pollution
WWF International
Avenue du Mont-Blanc
I196 Gland, Switzerland.

ADAM MARKHAM, Head

WWF International

1196 Gland, Switzerland.

\title{
The Halifax Declaration for a Sustainable Biosphere
}

At the invitation of the President, representatives from 33 universities in 10 countries on 4 continents assembled at Dalhousie University in Halifax, Nova Scotia, Canada, during 9-11 December 1991, under the auspices of Dalhousie University, the Association of Universities and Colleges of Canada, the International Association of Universities, and the United Nations University, to address the role of universities in the quest for environmentally sustainable development. They were joined by representatives of a number of academic and scholarly organizations as well as of government and business. At the conclusion of the meeting, the following statement was issued:

Human demands upon the planet Earth are now of a kind and volume that, unless they are changed and reduced substantially, will threaten the future well-being of all living species. Universities and their graduates must be significant actors if those demands are now to be shaped into the sustainable and equitable forms which will be necessary for a wholesome future environment and livable world.

As the international community marshals its endeavours for a sustainable future, focused upon the United Nations Conference on Environment and Development in Brazil in June 1992, universities in all countries are increasingly examining their own roles and responsibilities. At Talloires, France, in October 1990, a conference of university presidents from every inhabited continent, held under the auspices of Tufts University, issued a declaration of environmental commitment that has attracted the support of more than 100 universities in numerous countries. At Halifax, Canada, in December 1991, the specific challenge of environmentally sustainable development was addressed by the presidents of universities from Brazil, Canada, Indonesia, Zimbabwe, and elsewhere.

The Halifax meeting added its voice to those many others world-wide that are deeply concerned about the continuing widespread degradation of the Earth's environment, about the pervasive influence of poverty on the process, and about the unsustainable environmental practices that are now so widespread. The meeting expressed the belief that solutions to these problems can only be effective to the extent that the mutual vulnerability of all societies, in the South and in the North, East and West, is duly recognized, and that the energies and skills of people everywhere are employed in a positive, cooperative fashion. Because the educational, research, and public-service, roles of universities enable them to be competent and effective contributors to the major attitudinal and policy changes that are necessary for a sustainable future, the Dalhousie meeting urged the dedication of all universities to the following actions:

1) To ensure that the voice of your university is clear and uncompromising in its ongoing commitment to the principle and practice of sustainable development both within the university and at the local, national, and global, levels.

2) To utilize the intellectual resources of the university to encourage a much-improved understanding, on the part of society, of the interrelated physical, biological, 
and social, dangers facing the planet Earth and especially its Biosphere.

3) To emphasize the ethical obligation of the present generation to overcome those current malpractices of resource utilization and those widespread circumstances of intolerable human disparity and overpopulation which lie at the root of environmental unsustainability.

4) To establish whatever programmes are necessary within your university to generate the capability and the capacity necessary to develop appropriate environmental technologies and practices as well as to diminish environmental illiteracy and enhance ethical awareness on the part of staff, students, and the public at large.

5) To cooperate with one another and with all segments of society in the pursuit of practical, effective revision and reversals of those current practices which contribute to environmental degradation, to SouthNorth and other disparities, and to intergenerational inequity.

6) To employ all channels open to the university to communicate these undertakings to UNCED, to governments, and to the public at large.

\section{Howard C. Clark, President \\ $\&$}

MARILYN MACDONALD

Public Relations Office

Dalhousie University

Halifax

Nova Scotia B3H $3 J 5$

Canada.

\section{SCOPE Sustainable Biosphere Project: A Summary}

\section{The Imperative}

Throughout the world there has been an increasing awareness that environmental problems resulting from human activities threaten the future of this planet and especially its Biosphere.* The deteriorating state of our global environment, and the ever-increasing demands for resources by the growing human populations, mean that current attempts to prescribe rational approaches for sustaining The Biosphere* are simply inadequate. New approaches must be developed and implemented.

\section{The Challenge}

The SCOPE Sustainable Biosphere project is a new and bold approach to identify the most important knowledge that is necessary for so managing The Biosphere that it will be capable of supporting the next and future generations. In so doing, the Sustainable Biosphere project recognizes the striking dichotomy between the industrialized and the lessdeveloped countries in terms of their population and economic dynamics and the consequences of these asymmetries in resource use and misuse. Moreover, the Sustainable Biosphere project recognizes that time will be required to implement a strategy for sustaining The Biosphere and that the latter itself is not static but will be simultaneously changing in many ways.

\section{The Topics to be Considered}

Not even this innovative SCOPE project can consider all the issues that will need to be addressed; the list of the world's environmental problems is simply too long. Therefore, the SCOPE project is based on two fundamental guidelines for defining the most powerful approach:

A. The issues to be considered in the project will be based on three categories of environmental research priorities; and

B. These research priorities include human social and cultural dimensions as well as physical ones.

The three categories of research priorities emanating from an earlier report are as follows:

\footnotetext{
* With apologies to the SCOPE Secretariat, we are following our long-time custom of capitalizating these initials for dignified emphasis of what matters most. - Ed.
}

1) Diversity and Sustainability:

a) Ecosystem responses to disturbance

b) Consequences of simplification of ecosystems

c) Ways of maintaining diverse ecological systems

2) Sustaining a Changing Biosphere:

a) Evaluating the status of The Biosphere

b) Measuring responses and feedbacks of biotic systems to change

c) Synthesis of information and modelling processes that can be used to prescribe a sustainable Biosphere

3) Human Dimensions of Sustainability:

a) Human populations and renewable resources

b) Relationships between human values and beliefs and the use of natural resources

c) Relationships between environmental conditions and human cultural styles.

Although the details and emphases on these topics will be modified as the project develops, these are the main topics that will receive consideration in the project.

\section{Multidisciplinary Project}

The second fundamental guideline recognizes that these issues all have human social and cultural as well as environmental dimensions. Once again, no project can consider every dimension of every problem. Therefore, the SCOPE project will focus on environmental components but will include experts in economics and other social studies to ensure that these latter aspects are considered in each of the above topics. Involvement of these disciplines will be integral throughout the entire project, including membership of the Scientific Advisory Committee.

\section{Relation to Other Projects}

It is clear that although the focus of this project is primarily on the defined environmental issues, it is really a multidisciplinary effort embracing a wide variety of scientific and other disciplines making it necessary to treat the topics in such a way that there is a reasonable expectation of eventually designing and managing a sustainable Biosphere. Indeed, much of the inadequacy of some other current efforts is just the flaw that disciplines 